\title{
KEWENANGAN TERAPIS GIGI MULUT MENURUT PERMENKES NO. 20 TAHUN 2016 TENTANG IZIN DAN PENYELENGGARAAN PRAKTIK TERAPIS GIGI DAN MULUT DIHUBUNGKAN DENGAN KOMPETENSI TERAPIS GIGI MULUT DI WILAYAH KERJA PUSKESMAS KABUPATEN SUBANG
}

\author{
Devy Octaviana \\ Magister Ilmu Hukum Pascasarjana Unisba \\ Instruktur Jurusan Keperawatan Gigi Poltekkes Kemenkes Bandung \\ e-mail :devyoctaviana@yahoo.com
}

\begin{abstract}
Abstrak- Peraturan Menteri Kesehatan Nomor 20 tahun 2016 tentang Izin Dan Penyelenggaraan Praktik Terapis Gigi Dan Mulut, antara lain mengatur tentang kompetensi dan kewenangan terapis gigi dan mulut dalam tindakan. Beberapa Puskesmas di Kabupaten Subang terdapat suatu tindakan yang dilakukan terapis gigi mulut salah satunya pencabutan lebih dari satu akar dengan alasan saling membantu. Tujuan penelitian dari tesis ini untuk mendeskripsikan implementasi kewenangan dan upaya pelaksanaan terapis gigi mulut menurut Permenkes Nomor 20 tahun 2016 tentang Izin dan Penyelenggaraan Praktik Terapis Gigi dan Mulut dihubungkan dengan kompetensi terapis gigi mulut di wilayah kerja Puskesmas kabupaten Subang. Metode pendekatan yang digunakan dalam penelitian ini adalah yurudis normatif, dengan menganalisis data sekunder yang terdiri dari bahan-bahan hukum primer, bahan hukum sekunder, dan bahan hukum tersier yang diperoleh dari studi kepustakaan, kemudian data yang diperoleh tersebut dianalisis menggunakan metode yuridis kualitatif. Hasil dari penelitian bahwa implementasi kewenangan terapis gigi mulut dalam melakukan tindakan ada beberapa yang sesuai dan ada beberapa yang tidak sesuai dengan Peraturan Menteri Keseharan Nomor 20 Tahun 2016 tentang Izin dan Penyelenggaraan Praktik Terapis Gigi dan Mulut. Upaya menangani pelaksanaan kewenangan terapis gigi mulut meliputi mempertegas aturan agar dilaksanakan secara berkesinambungan, melakukan pembinaan melalui pelatihan, melakukan pengawasan agar tertib dalam hal kewenangan sesuai kompetensi.
\end{abstract}

\section{Kata Kunci : Kewenangan, Kompetensi, Terapis Gigi Mulut}

Abstract- Regulation of the Minister of Health Number 20 Year 2016 concerning Practice Permission and Implementation of Oral Dental Therapist to regulate the competency and authority of oral dental therapists in action. Some Community Health Center (Puskesmas) in Subang District has an action conducted by oral dental therapists, one of which is the teeth removal of more than one root with the reason for mutual assistance. This study aimed at describing the implementation of authority and efforts to implement oral dental therapists according to regulation of the Minister of Health Number 20 Year 2016 concerning Practice Permission and Implementation of Oral Dental Therapist related to the competency of oral dental therapists in the working area of Puskesmas in Subang District. The method used normative juridical by analyzing secondary data consisting of primary legal materials, secondary legal materials, and tertiary legal materials obtained from literature study and then analyzed using qualitative juridical method. The result of this study shows that the implementation of the authority of oral dental therapists in carrying out the actions were not all appropriate and following the regulation of the Minister of Health Number 20 Year 2016 concerning Practice Permission and Implementation of Oral Dental Therapist. The efforts to deal with the implementation of oral dental therapist authority included emphasizing the rules to be implemented sustainably, conducting coaching through training, and supervising in an orderly manner in terms of authority in accordance with competencies.

Keywords: Authority, Competence, Oral Dental Therapist 


\section{A. PENDAHULUAN}

Indonesia merupakan salah satu negara berkembang yang sedang giat-giatnya menggalang pembangunan di segala bidang, salah satunya pembangunan kesehatan. Hal ini sesuai upaya nasional dalam Rencana Pembangunan Jangka Panjang bidang Kesehatan (RPJPK) 2005 2025 yang bertujuan meningkatkan kesadaran, kemauan, kemampuan hidup sehat bagi setiap orang agar peningkatan derajat kesehatan masyarakat yang setinggi - tingginya dapat terwujud. Hal ini salah satunya ditandai oleh penduduknya memiliki kemampuan untuk menjangkau pelayanan kesehatan yang bermutu, secara adil dan merata. ${ }^{1}$

Kesehatan merupakan unsur terpenting dalam kehidupan manusia. Pasal 52 Undang - Undang RI No. 36 tahun 2009 tentang Kesehatan yang dimaksud upaya kesehatan adalah setiap kegiatan yang dilakukan secara terpadu, terintegrasi dan berkesinambungan untuk memelihara dan meningkatkan derajat kesehatan masyarakat dalam bentuk pencegahan penyakit, peningkatan kesehatan, pengobatan penyakit, dan pemulihan

\footnotetext{
${ }^{1}$ Rencana Pembangunan Jangka Panjang Bidang Kesehatan 2005 - 2025 (Depkes RI 2009).
}

kesehatan oleh pemerintah dan masyarakat. $^{2}$

Menurut Undang-Undang RI No. 36 Tahun 2014 Tentang Tenaga Kesehatan, yang dimaksud tenaga kesehatan adalah setiap orang yang mengabdikan diri dalam bidang kesehatan serta memiliki pengetahuan dan/ atau keterampilan melalui pendidikan di bidang kesehatan yang untuk jenis tertentu memerlukan kewenangan untuk melakukan upaya kesehatan. ${ }^{3}$

Menurut Keputusan Menteri Kesehatan Nomor 1035 / MENKES / SK / IX / 1998 tentang Perawat Gigi menyatakan bahwa Perawat Gigi merupakan salah satu jenis tenaga kesehatan dalam kelompok keperawatan yang dalam menjalankan tugas profesinya harus berdasarkan Standar Profesi. Pasal 11 ayat (11) Undang - Undang Nomor 36 tahun 2014 tentang Tenaga Kesehatan, profesi perawat gigi berubah nomenklatur menjadi terapis gigi dan mulut.

Setiap orang berhak hidup sejahtera lahir dan batin, bertempat tinggal, dan mendapatkan lingkungan hidup yang baik dan sehat serta berhak memperoleh

\footnotetext{
${ }^{2}$ Undang - Undang RI No 36 Tahun 2009 Tentang Kesehatan.

${ }^{3}$ Undang - Undang RI Nomor 36 Tahun 2014 Tentang Tenaga Kesehatan.
} 
pelayanan kesehatan. ${ }^{4}$ Salah satu aspek penting dalam pembangunan kesehatan adalah sumber daya manusia, oleh karenanya, dalam rangka mengatasi masalah kesehatan gigi dan mulut diperlukan tenaga kesehatan yang kompeten sehingga dapat berkontribusi mengatasi permasalahan kesehatan gigi dan mulut tersebut. Terapis gigi dan mulut adalah salah satu tenaga kesehatan yang mempunyai peran signifikan dalam mengatasi permasalahan kesehatan gigi dan mulut.

Di Indonesia, jumlah tenaga terapis gigi dan mulut masih sangat kurang jika dibandingkan dengan jumlah total penduduk. Jumlah penduduk Indonesia per 30 Juni 2016 adalah 257.912.349 jiwa. Jika mengacu pada kebutuhan asuhan keperawatan gigi dan mulut dengan rasio 158 Terapis Gigi dan Mulut per 100.000 penduduk pada tahun 2025 maka dibutuhkan 477.137 orang Terapis Gigi dan Mulut. Berdasarkan data Majelis Tenaga Kesehatan Indonesia (MTKI) tahun 2015, jumlah Terapis Gigi dan Mulut teregistrasi adalah sebanyak 17.027 orang. Dengan demikian saat ini Indonesia masih kekurangan sekitar 460.110 orang Terapis Gigi dan Mulut. ${ }^{5}$

\footnotetext{
${ }^{4}$ Undang - Undang Dasar 1945 Pasal 28 H ayat (1)

Tentang Hak Asasi Manusia (1945)

${ }^{5}$ Standar Kompetensi Terapis Gigi dan Mulut Indonesia (DPP PPGI 2017).
}

Pelaksanaan tugas tenaga kesehatan hanya didasarkan pada pengetahuan, keterampilan dan sikap yang diperoleh dalam pendidikan. Hal ini menyulitkan tenaga kesehatan dalam menghadapi tuntutan dari pihak lain karena malpraktek dan penyimpangan pelaksanaan tugasnya serta kurang menghormati hak pasien. ${ }^{6}$

Ukuran keberhasilan penyelanggaraan kesehatan ditentukan oleh tingkat kepuasan pasien. Kepuasan pasien dicapai apabila penerima pelayanan memperoleh pelayanan sesuai dengan yang dibutuhkan dan diharapkan maka pasien juga mengharapkan adanya pelayanan yang bermutu, karena dengan pelayanan yang bermutu maka pelanggan akan merasa puas. Menurut Azwar bahwa yang dimaksud dengan mutu pelayanan kesehatan adalah yang menujuk pada tingkat kesempurnaan pelayanan kesehatan yang di satu pihak dapat menimbulkan kepuasan pada setiap pasien serta di pihak lain tata cara penyelenggaraannya sesuai kode etik dan standar pelayanan professional yang telah ditetapkan. ${ }^{7}$

Upaya pemerintah agar warga negara mendapat pelayanan kesehatan adalah

\footnotetext{
${ }^{6}$ Upaya revitalisasi pelayanan

kesehatan Puskesmas dan jaringannya dalam rangka peningkatan kualitas pelayanan kesehatan (Handayani L, Sopacua E, Siswanto, Ma'ruf NA \&Widjiartini 2006).

${ }^{7}$ Pengantar Administrasi Kesehatan (Azrul Azwar 1996).
} 
dengan membuat fasilitas pelayanan kesehatan yang mudah dijangkau oleh masyarakat seperti puskesmas. Fasilitas pelayanan kesehatan adalah suatu alat dan/atau tempat yang digunakan untuk menyelenggarakan upaya pelayanan kesehatan, baik promotif, preventif, kuratif, maupun rehabilitative yang dilakukan oleh pemerintah, pemerintah daerah, dan/atau masyarakat. ${ }^{8}$

Pusat Kesehatan Masyarakat (PUSKESMAS) merupakan salah satu sarana pelayanan kesehatan yang menjadi andalan atau tolak ukur dari pembangunan kesehatan, sarana peran serta masyarakat, dan pusat pelayanan pertama yang menyeluruh dari suatu wilayah. ${ }^{9}$

$\begin{array}{cccc}\text { Pasal } & 23 & \text { Permenkes } & \text { No. } \\ \text { 2052/Menkes/Per/X/2011 tentang } & \text { Izin }\end{array}$

Praktik dan Pelaksanaan Praktik Kedokteran, menetapkan syarat-syarat untuk sahnya pelimpahan kewenangan tindakan kedokteran gigi kepada terapis gigi mulut, yaitu antara lain: pelimpahan dilakukan secara tertulis. Pelimpahan tindakan sebagaimana dimaksud pada ayat (1) dilakukan dengan ketentuan: tindakan yang dilimpahkan termasuk dalam kemampuan dan keterampilan yang telah

\footnotetext{
${ }^{8}$ Permenkes Nomor 80 Tahun 2016 Tentang Penyelenggaraan Pekerjaan Asisten Tenaga Kesehatan.

${ }^{9}$ Manajemen Pelayanan Kesehatan (Dedi Alamsyah 2011).
}

dimiliki oleh penerima pelimpahan, pelaksanaan tindakan yang dilimpahkan tetap di bawah pengawasan pemberi pelimpahan, pemberi pelimpahan tetap bertanggung jawab atas tindakan yang dilimpahkan sepanjang pelaksanaan tindakan sesuai dengan pelimpahan yang diberikan, tindakan yang dilimpahkan tidak termasuk mengambil keputusan klinis sebagai dasar pelaksanaan tindakan dan tindakan yang dilimpahkan tidak bersifat terus menerus.

Tugas pokok terapis gigi dan mulut berdasarkan Peraturan Menteri Kesehatan Nomor 20 tahun 2016 tentang Izin dan Penyelenggaraan Praktik Terapis Gigi dan Mulut adalah melaksanakan pelayanan asuhan kesehatan gigi dan mulut di bidang promotif, preventif, dan kuratif sederhana untuk meningkatkan derajat kesehatan gigi dan mulut yang optimal pada individu, kelompok dan masyarakat. ${ }^{10}$

Berdasarkan kajian peran, fungsi serta tugas pokok terapis gigi dan mulut, kebutuhan pelayanan kesehatan gigi dan mulut di fasilitas pelayanan kesehatan serta benchmarking area kompetensi dental hygienist \& oral health therapist internasional, area kompetensi terapis gigi dan mulut Indonesia terdiri dari

\footnotetext{
${ }^{10}$ Permenkes Nomor 20 Tahun 2016 Tentang Izin dan Penyelenggaraan Praktik Terapis Gigi dan Mulut.
} 
profesionalisme dan kepatuhan hukum, keterampilan sosial komunikasi dan pengelolaan informasi, berpikir kritis dan pengembangan diri, landasan ilmiah ilmu asuhan kesehatan gigi \& mulut, keterampilan klinik asuhan kesehatan gigi \& mulut, pengelolaan asuhan kesehatan gigi \& mulut.

Pemberian kewenangan/pendelegasian wewenang yang diberikan oleh dokter gigi kepada perawat gigi untuk memutuskan bentuk pelayanan yang diberikan kepada masyarakat maupun pembagian tanggungjawab dengan dokter gigi atau tugas-tugas kolaborasi dalam memberikan pelayanan kesehatan gigi dan mulut akan membuahkan konsekuensi hukum.

Jumlah Puskesmas di Indonesia sampai dengan Desember 2016 adalah 9.767 unit, yang terdiri dari 3.411 unit Puskesmas rawat inap dan 6.356 unit Puskesmas non rawat inap. Di Puskesmas terdapat macam - macam pelayanan kesehatan diantaranya pelayanan gigi.

Jumlah dokter gigi di Puskesmas minimal satu orang, baik di puskesmas rawat inap dan non rawat inap dan di wilayah perkotaan, perdesaan, maupun di kawasan terpencil dan sangat terpencil. Di Indonesia pada tahun 2016 , terdapat $11 \%$ Puskesmas melebihi jumlah standar dokter gigi, 41,3\% Puskesmas dengan jumlah dokter gigi cukup, dan 43,2\% Puskesmas tidak memiliki dokter gigi. Berdasarkan regional, proporsi terbesar Puskesmas dengan dokter gigi cukup dan lebih terdapat di regional Jawa-Bali $(69,4 \%)$ dan Sumatera $(52,2 \%){ }^{11}$

Data yang didapatkan bahwa 40 Puskesmas kabupaten Subang hanya 18 puskesmas yang ada dokter gigi, 22 Puskesmas yang tidak ada dokter gigi. Tentunya terapis gigi mulut di 22 Puskesmas kabupaten Subang bekerja tanpa ada dokter gigi, sedangkan terapis gigi mulut dituntut untuk bekerja sesuai kompetensi.

Berdasarkan Peraturan Daerah Kabupaten Subang Nomor 3 Tahun 2007 tentang Pemekaran dan Pembentukan Wilayah Kerja Kecamatan di Lingkungan Pemerintah Kabupaten Subang, Wilayah Kabupaten Subang terbagi menjadi 30 kecamatan, yang dibagi lagi menjadi 245 desa dan 8 kelurahan. Pusat pemerintahan di Kecamatan Subang. Kabupaten Subang adalah sebuah kabupaten di Tatar Pasundan provinsi Jawa Barat, Indonesia. Ibukotanya adalah Subang. Luas:

\footnotetext{
${ }^{11}$ Sumber Pusat Data dan Informasi (Kemenkes RI 2017).
} 
$1.894 \mathrm{~km}^{2}$, provinsiJawa Barat, Jumlah penduduk: 1,529 juta (2015). ${ }^{12}$

\section{Di Puskesmas Kabupaten Subang} terdapat kasus kompetensi dokter gigi yang dikerjakan oleh terapis gigi mulut. Seorang terapis gigi mulut harus bersedia melakukan tindakan di luar kompetensi dengan cara pelimpahan wewenang dari dokter gigi secara lisan. Di Puskesmas tidak semua ada dokter gigi ataupun jika ada dokter gigi, lebih ke arah struktural dimana dokter gigi ada yang merangkap tugas serta saling membantu.

Permenkes No. 20 tahun 2016 tentang izin dan penyelenggaraan praktik terapis gigi dan mulut Pasal 16 bahwa pelayanan kesehatan dasar pada kasus kesehatan gigi terbatas meliputi pencabutan gigi sulung dan gigi tetap satu akar dengan local anestesi, penambalan gigi satu atau dua bidang dengan glass ionomer atau bahan lainnya, dan perawatan pasca tindakan. Permenkes No. 20 tahun 2016 tentang izin dan penyelenggaraan praktik terapis gigi dan mulut Pasal 18 menjelaskan bahwa pelimpahan wewenang bagi terapis gigi mulut dalam pelaksanaan pelayanan dimana pelayanan dilakukan di bawah pengawasan atas pelimpahan wewenang secara mandat dari dokter gigi atau

\footnotetext{
${ }^{12}$ Peraturan Daerah Kabupaten Subang Nomor 3

Tahun 2007.
}

berdasarkan penugasan pemerintah sesuai kebutuhan. Permenkes No. 20 tahun 2016 tentang izin dan penyelenggaraan praktik terapis gigi dan mulut Pasal 19 juga menjelaskan tentang pelimpahan wewenang secara mandat dari dokter gigi meliputi penambalan gigi lebih dari dua bidang, perawatan saluran akar, dan pemberian resep dan obat-obatan. Permenkes No. 20 tahun 2016 tentang izin dan penyelenggaraan praktik terapis gigi dan mulut Pasal 20 (2) Pelayanan dalam rangka pelimpahan wewenang sebagaimana dimaksud pada ayat (1) hanya dapat dilakukan oleh Terapis Gigi dan Mulut yang telah mendapat pelatihan. Permenkes No. 20 tahun 2016 tentang izin dan penyelenggaraan praktik terapis gigi dan mulut Pasal 20 ayat (3) Pelayanan dalam rangka pelimpahan wewenang sebagaimana dimaksud pada ayat (2) meliputi pelayanan kesehatan dan mulut sesuai dengan kompetensi tambahan yang diperoleh melalui pelatihan. ${ }^{13}$

Permenkes No. 20 tahun 2016 tentang izin dan penyelenggaraan praktik terapis gigi dan mulut Pasal 20 ayat (4) Pelatihan sebagaimana dimaksud pada ayat (2) dan ayat (3) merupakan tanggung jawab pemerintah daerah provinsi dan/atau pemerintah daerah kabupaten/kota bekerja

\footnotetext{
${ }^{13}$ Ibid.
} 
sama dengan Organisasi Profesi dan melibatkan organisasi profesi terkait lainnya. Permenkes No. 20 tahun 2016 tentang izin dan penyelenggaraan praktik terapis gigi dan mulut Pasal 20 ayat (5) Pelatihan sebagaimana dimaksud pada ayat (2) dan ayat (4) harus terakreditasi sesuai ketentuan peraturan perundang undangan. Permenkes No. 20 tahun 2016 tentang izin dan penyelenggaraan praktik terapis gigi dan mulut Pasal 20 ayat (6) Pelimpahan wewenang berdasarkan penugasan pemerintah hanya dapat dilaksanakan di Fasilitas Pelayanan Kesehatan milik Pemerintah dan/atau pemerintah daerah.

Permenkes No. 20 tahun 2016 tentang izin dan penyelenggaraan praktik terapis gigi dan mulut Pasal 21 menetapkan dalam hal daerah sebagaimana dimaksud dalam pasal 20 ayat (1) terdapat dokter gigi, wewenang untuk melakukan pelayanan berdasarkan penugasan pemerintah tidak berlaku, terdapat tindakan pencabutan tiga akar yang harusnya dilakukan oleh dokter gigi tetapi dikerjakan oleh terapis gigi mulut dengan alasan pelimpahan wewenang atau tidak adanya dokter gigi di puskesmas antara lain terdapat di beberapa di Puskesmas Kabupaten Subang. ${ }^{14}$

\footnotetext{
${ }^{14}$ Ibid.
}

Berdasarkan hal-hal di atas, perlu diadakan pengkajian lebih lanjut tentang "Kewenangan Terapis Gigi Mulut Menurut Permenkes No.20 Tahun 2016 Tentang Izin dan Penyelenggaraan Praktik Terapis Gigi dan Mulut Dihubungkan Dengan Kompetensi Terapis Gigi Mulut Di Wilayah Kerja Puskesmas Kabupaten Subang”.

\section{Identifikasi Masalah}

1. Bagaimana implementasi kewenangan terapis gigi mulut menurut Permenkes No.20 tahun 2016 tentang Izin dan Penyelenggaraan Praktik Terapis Gigi dan Mulut dihubungkan dengan kompetensi terapis gigi mulut di wilayah kerja Puskesmas kabupaten Subang?

2. Bagaimana upaya menangani pelaksanaan kewenangan terapis gigi mulut menurut Permenkes No.20 tahun 2016 tentang Izin dan Penyelenggaraan Praktik Terapis Gigi dan Mulut dihubungkan dengan kompetensi terapis gigi mulut di wilayah kerja Puskesmas kabupaten Subang?

\section{Tujuan Penelitian}

1. Memahami implementasi kewenangan terapis gigi mulut menurut Permenkes No.20 tahun 2016 tentang Izin dan Penyelenggaraan Praktik Terapis Gigi dan Mulut dihubungkan dengan 
kompetensi terapis gigi mulut di wilayah kerja Puskesmas kabupaten Subang?

2. Memahami upaya menangani pelaksanaan kewenangan terapis gigi mulut menurut Permenkes No.20 tahun 2016 tentang Izin dan Penyelenggaraan Praktik Terapis Gigi dan Mulut dihubungkan dengan kompetensi terapis gigi mulut di wilayah kerja Puskesmas kabupaten Subang?

\section{B. PEMBAHASAN}

Menurut WHO (World Health Organization) Kesehatan adalah suatu keadaan fisik, mental, dan sosial kesejahteraan dan bukan hanya tidak adanya penyakit atau kelemahan dalam hal ini kesehatan yang ada di Kabupaten Subang. Berdasarkan Peraturan Daerah Kabupaten Subang Nomor 3 Tahun 2007 tentang Pemekaran dan Pembentukan Wilayah Kerja Kecamatan di Lingkungan Pemerintah Kabupaten Subang, Wilayah Kabupaten Subang terbagi menjadi 30 kecamatan, yang dibagi lagi menjadi 245 desa dan 8 kelurahan. Pusat pemerintahan di Kecamatan Subang. Kabupaten Subang adalah sebuah kabupaten di Tatar Pasundan provinsi Jawa Barat, Indonesia. Ibukotanya adalah Subang. Luas:
$1.894 \mathrm{~km}^{2}$, provinsiJawa Barat, Jumlah penduduk: 1,529 juta (2015). ${ }^{15}$

Data penelitian yang diambil berbentuk wawancara dengan mengambil sampel di lapangan khususnya di Kabupaten Subang. Sampelnya sebanyak dua Puskesmas yang ada dokter gigi dan terapis gigi mulut, dua Puskesmas yang tidak ada dokter gigi dan hanya ada tarapis gigi mulut serta satu bagian kepegawaian Dinas Kabupaten Subang. Mereka sebenarnya mengetahui mana yang harus dan boleh dilakukan serta yang tidak boleh dilakukan, namun karena adanya hambatan dalam proses belajar untuk memahami dan memaknai suatu norma hukum maka tujuan dalam normanorma yang terkandung dalam ketentuan hukum tersebut tidak akan dapat tercapai. Hambatan-hambatan dalam proses belajar seseorang itu, sangat dipengaruhi oleh lingkungan sosial dan budaya (faktor eksternal) dimana seseorang tersebut berada, karena kedua faktor tersebut memiliki peran yang paling besar dalam membentuk perilaku manusia. Sedangkan faktor internal yang menentukan seseorang itu merespon stimulasi dari luar, yaitu perhatian, pengamatan, persepsi, motivasi, fantasi, sugesti, dan sebagainya. ${ }^{16}$

\footnotetext{
${ }^{15}$ Peraturan Daerah Kabupaten Subang Nomor 3 Tahun 2007.

${ }^{16}$ Ilmu Perilaku Kesehatan (Soekidjo Notoatmojo 2010).
} 
1. Puskesmas Karanganyar

Puskesmas Karanganyar terletak di SDN Perumnas I, Karanganyar, Kecamatan Subang, Kabupaten Subang, Jawa Barat, Indonesia 41211. Rata - rata kunjungan pasien poli gigi di Puskesmas Karanganyar perhari sebanyak 8 orang. Puskesmas ini hanya terdapat terapis gigi mulut. Terapis gigi mulut terkadang mengerjakan tindakan pencabutan lebih dari satu akar dikarenakan tidak ada dokter gigi tetapi terkadang yang terlihat susah, terapis gigi mulut melakukan rujukan.

Visi Misi tertuang dalam mewujudkan Puskesmas Karanganyar yang berkualitas berbasis gotong royong berwawasan lingkungan menuju masyarakat pusakajaya yang sehat dan mandiri pada tahun 2030.

\section{Puskesmas Pusakanegara}

Pusakanagara Kabupaten Subang terletak di Desa Pusakaratu dengan wilayah kerjanya meliputi 7 Desa diantaranya : Pusakaratu, Gempol, Kalentambo, Rancadaka, Patimban, Kotasari dan Mundusari. Dan berbatasan langsung di Sebelah Utara dengan Laut Jawa. Luas Wilayah Kerja Puskesmas Pusakanagara setelah terjadi pemekaran menjadi dua kecamatan yakni Kecamatan Pusakajaya yakni 5142 KM2. Menurut data yang diperoleh dari Kantor Kecamatan Pusakanagara Jumlah Penduduk mencapai 39.027 ( th 2008 ) dengan 11.270 KK. Dengan adanya sarana dan prasarana jalan yang memadai dari dan menuju ke Puskesmas Pusakanagara sehingga pelayanan kesehatan dari tahun ke tahun semakin meningkat. ${ }^{17}$

Rata - rata kunjungan pasien poli gigi di Puskesmas Pusakanegara perhari sebanyak 15 orang. Puskesmas ini hanya terdapat terapis gigi mulut. Terapis gigi mulut mengerjakannya sudah sesuai kompetensi, sedangkan yang tidak sesuai dilakukan rujukan.

Visi : Mewujudkan masyarakat kecamatan Pusakanegara yang mandiri untuk hidup sehat tahun 2022.

Misi :

a. Mendorong kemandirian masyarakat untuk berprilaku hidup bersih dan sehat

b. Melaksanakan pemberdayaan masyarakat dalam bidang kesehatan melalui UKBM (Upaya Kesehatan Berbasis Masyarakat)

c. Menjalin kemitraan dengan lintas sektor dalam pelaksanaan upaya kesehatan masyarakat

d. Meningkatkan kwalitas sumber daya manusia

e. Menyelenggarakan pelayanan kesehatan tingkat pertama secara professional, bermutu, terjangkau dan merata.

\footnotetext{
${ }^{17} \mathrm{http}: / /$ pkmpusakanagara.blogspot.com/2009/06/pr ofil-pkm-pusakanagara_08.html
} 
3. Puskesmas Ciasem

Puskesmas Ciasem terletak di Jalan Raya Ciasem Subang, Sukamandijaya, Ciasem, Kabupaten Subang, Jawa Barat 41256, Indonesia Puskesmas ini terdapat dokter gigi dan terapis gigi mulut. Rata rata kunjungan pasien poli gigi di Puskesmas Ciasem perhari sebanyak 26 orang. Terapis gigi mulut melakukan tindakan di luar kompetensi dengan alasan kolaborasi / saling membantu dengan banyaknya pasien setiap hari. Dikatakan banyak karena terkadang terdapat tindakan yang sulit. Jika dilakukan dokter gigi sendirian tidak akan selesai jadi terapis gigi mulut juga melakukan tindakan dokter gigi tersebut dan kalau bisa perlu ditambahi dokter gigi.

Visi : Terwujudnya Puskesmas Pantura BERSERI (BERsih, Sehat, Efektif, Responsif, Inovatif) menuju terwujudnya Gapura Serasi.

Misi :

a. Menggerakkan masyarakat dalam bidang pembangunan berwawasan kesehatan

b. Memberdayakan masyarakat dan keluarga dalam peningkatan hidup bersih serta lingkungan sehat

c. Menggalang kemitraan dengan berbagai pihak dalam mewujudkan masyarakat pantura berseri.

4. Puskesmas Pamanukan
Puskesmas Pamanukan terletak di Jalan Jon Martasasmita No. 30, Kecamatan Pamanukan, Subang, Jawa Barat, Indonesia 41254. Rata - rata kunjungan pasien poli gigi di Puskesmas Pamanukan perhari sebanyak 15 orang. Puskesmas ini terdapat dokter gigi dan terapis gigi mulut. Terapis gigi mulut juga melakukan tindakan di luar kompetensi dengan alasan saling membantu dokter gigi.

Visi : Terwujudnya Masyarakat Pamanukan yang sehat, mandiri dan gotong royong Tahun 2022.

Misi :

a. Menggerakan masyarakat dalam bidang pembangunan berwawasan kesehatan

b. Memberdayakan masyarakat dalam berprilaku hidup bersih dan sehat serta meningkatkan STBM (Sanitasi Total Berbasis Masyarakat)

c. Menjadi puskesmas terdepan dalam penanggulangan pelayanan HIVAIDS

d. Menggalang kemitraan dengan berbagai pihak dalam mewujudkan masyarakat yang sehat, mandiri dan gotong royong.

5. Dinas Kesehatan Kabupaten Subang

Dalam penanganan jumlah formasi tenaga kesehatan, Dinas Kesehatan Kabupaten Subang telah menyediakan aplikasi untuk pengajuan formasi dari masing - masing instansi. Tapi perlu 
diketahui, tidak semua pengajuan di terima karena perlu dipertimbangkan juga dari kuota pasien dan lain - lain. Dan pernah dibuka formasi, terkadang tidak terisi dikarenakan peserta tidak lolos / tidak ada pendaftar.

\section{Tabel 1.1}

Pelayanan kesehatan dasar pada kasus kesehatan gigi terbatas meliputi pencabutan gigi sulung dan gigi tetap satu akar dengan lokal anestesi, penambalan gigi satu atau dua bidang dengan glass ionomer atau bahan lainnya, dan perawatan pasca tindakan (Permenkes Nomor 20 Tahun 2016 Pasal 16) ${ }^{18}$

\begin{tabular}{|c|c|c|c|c|}
\hline No. & Puskesmas & $\begin{array}{c}\text { Ses } \\
\text { uai }\end{array}$ & $\begin{array}{c}\text { Tidak } \\
\text { Sesuai }\end{array}$ & $\begin{array}{c}\text { Hambatan } \\
\text { / Kendala }\end{array}$ \\
\hline 1. & $\begin{array}{c}\text { Puskesmas } \\
\text { Karanganyar }\end{array}$ & $\mathrm{v}$ & - & $\begin{array}{c}\text { Tidak ada } \\
\text { dokter gigi }\end{array}$ \\
\hline 2. & $\begin{array}{c}\text { Puskesmas } \\
\text { Pusakanegara }\end{array}$ & $\mathrm{v}$ & - & $\begin{array}{c}\text { Tidak ada } \\
\text { dokter gigi } \\
\text { tetapi } \\
\text { dilakukan } \\
\text { rujukan }\end{array}$ \\
\hline 3. & $\begin{array}{c}\text { Puskesmas } \\
\text { Pamanukan }\end{array}$ & $\mathrm{v}$ & - & $\begin{array}{c}\text { Saling } \\
\text { membantu }\end{array}$ \\
\hline
\end{tabular}

Tabel 1.2

Terapis gigi mulut dapat melaksanakan pelayanan di bawah pengawasan atas pelimpahan wewenang secara mandat dari dokter gigi, atau berdasarkan penugasan pemerintah sesuai kebutuhan (Permenkes Nomor 20 Tahun 2016 Pasal 18) ${ }^{19}$

\begin{tabular}{|c|c|c|c|c|}
\hline No & Puskesmas & $\begin{array}{c}\text { Ses } \\
\text { uai }\end{array}$ & $\begin{array}{c}\text { Tidak } \\
\text { Sesuai }\end{array}$ & $\begin{array}{c}\text { Hambatan } \\
\text { / Kendala }\end{array}$ \\
\hline
\end{tabular}

\footnotetext{
${ }^{18}$ Hasil penelitian diolah

${ }^{19}$ Hasil penelitian diolah
}

\begin{tabular}{|c|c|c|c|c|} 
1. & $\begin{array}{c}\text { Puskesmas } \\
\text { Karanganya } \\
\mathrm{r}\end{array}$ & - & $\mathrm{v}$ & $\begin{array}{c}\text { Tidak ada } \\
\text { dokter gigi }\end{array}$ \\
\hline 2. & $\begin{array}{c}\text { Puskesmas } \\
\text { Pusakanega } \\
\text { ra }\end{array}$ & - & $\mathrm{v}$ & $\begin{array}{c}\text { Tidak ada } \\
\text { dokter gigi }\end{array}$ \\
\hline 3. & $\begin{array}{c}\text { Puskesmas } \\
\text { Ciasem }\end{array}$ & $\mathrm{v}$ & $\mathrm{v}$ & $\begin{array}{c}\text { Banyaknya } \\
\text { pasien } \\
\text { sehingga } \\
\text { saling } \\
\text { membantu }\end{array}$ \\
\hline 4. & $\begin{array}{c}\text { Puskesmas } \\
\text { Pamanukan }\end{array}$ & $\mathrm{v}$ & $\mathrm{v}$ & $\begin{array}{c}\text { Saling } \\
\text { membantu }\end{array}$ \\
\hline
\end{tabular}

Tabel 1.3

Pelimpahan wewenang secara mandat dari dokter gigi sebagaimana dimaksud dalam Pasal 18 huruf a meliputi : penambalan gigi lebih dari dua bidang, perawatan saluran akar, dan pemberian resep dan obat - obatan (Permenkes Nomor 20 Tahun 2016 Pasal 19) ${ }^{20}$

\begin{tabular}{|c|c|c|c|c|}
\hline No. & Puskesmas & $\begin{array}{c}\text { Ses } \\
\text { uai }\end{array}$ & $\begin{array}{c}\text { Tidak } \\
\text { Sesuai }\end{array}$ & $\begin{array}{c}\text { Hambatan } \\
\text { / Kendala }\end{array}$ \\
\hline 1. & $\begin{array}{c}\text { Puskesmas } \\
\text { Karanganya } \\
\text { r }\end{array}$ & - & - & $\begin{array}{c}\text { Tidak ada } \\
\text { dokter gigi }\end{array}$ \\
\hline 2. & $\begin{array}{c}\text { Puskesmas } \\
\text { Pusakanega } \\
\text { ra }\end{array}$ & - & - & $\begin{array}{c}\text { Tidak ada } \\
\text { dokter gigi }\end{array}$ \\
\hline 3. & $\begin{array}{c}\text { Puskesmas } \\
\text { Ciasem }\end{array}$ & $\mathrm{v}$ & $\mathrm{v}$ & $\begin{array}{c}\text { Banyaknya } \\
\text { pasien } \\
\text { sehingga } \\
\text { saling } \\
\text { membantu }\end{array}$ \\
\hline 4. & $\begin{array}{c}\text { Puskesmas } \\
\text { Pamanukan }\end{array}$ & $\mathrm{v}$ & $\mathrm{v}$ & $\begin{array}{c}\text { Saling } \\
\text { membantu }\end{array}$ \\
\hline
\end{tabular}

Tabel 1.4

Pelimpahan wewenang berdasarkan penugasan pemerintah sebagaimana dimaksud dalam Pasal 18 huruf b dilakukan dalam hal tidak terdapat dokter gigi di suatu daerah (Permenkes Nomor 20 Tahun 2016 Pasal 20 ayat 1) ${ }^{21}$

\footnotetext{
${ }^{20}$ Hasil penelitian diolah

${ }^{21}$ Hasil penelitian diolah
} 


\begin{tabular}{|c|c|c|c|c|}
\hline No. & Puskesmas & $\begin{array}{l}\text { Ses } \\
\text { uai }\end{array}$ & $\begin{array}{l}\text { Tidak } \\
\text { Sesuai }\end{array}$ & $\begin{array}{c}\text { Hambatan } \\
/ \\
\text { Kendal } \\
\text { a }\end{array}$ \\
\hline 1. & $\begin{array}{c}\text { Puskesmas } \\
\text { Karanganya } \\
\text { r }\end{array}$ & - & - & $\begin{array}{l}\text { Tidak ada } \\
\text { dokter gigi }\end{array}$ \\
\hline 2. & $\begin{array}{c}\text { Puskesmas } \\
\text { Pusakanega } \\
\text { ra }\end{array}$ & - & - & $\begin{array}{l}\text { Tidak ada } \\
\text { dokter gigi }\end{array}$ \\
\hline 3. & $\begin{array}{l}\text { Puskesmas } \\
\text { Ciasem }\end{array}$ & - & V & $\begin{array}{l}\text { Banyaknya } \\
\text { pasien } \\
\text { sehingga } \\
\text { saling } \\
\text { membantu }\end{array}$ \\
\hline 4. & $\begin{array}{l}\text { Puskesmas } \\
\text { Pamanukan }\end{array}$ & - & $\mathrm{V}$ & $\begin{array}{c}\text { Saling } \\
\text { membantu }\end{array}$ \\
\hline
\end{tabular}

Tabel 1.5

Pelayanan dalam rangka pelimpahan wewenang sebagaimana dimaksud pada ayat (1) hanya dapat dilakukan oleh terapis gigi dan mulut yang telah mendapat pelatihan (Permenkes Nomor 20 Tahun 2016 Pasal 20 ayat 2)

\begin{tabular}{|c|c|c|c|c|}
\hline No. & Puskesmas & $\begin{array}{c}\text { Ses } \\
\text { uai }\end{array}$ & $\begin{array}{c}\text { Tidak } \\
\text { Sesuai }\end{array}$ & $\begin{array}{c}\text { Hambatan } \\
\text { / Kendala }\end{array}$ \\
\hline 1. & $\begin{array}{c}\text { Puskesmas } \\
\text { Karanganya } \\
\mathrm{r}\end{array}$ & - & $\mathrm{v}$ & $\begin{array}{c}\text { Tidak ada } \\
\text { dokter gigi }\end{array}$ \\
\hline 3. & $\begin{array}{c}\text { Puskesmas } \\
\text { Pusakanega } \\
\text { ra }\end{array}$ & - & $\mathrm{v}$ & $\begin{array}{c}\text { Tidak ada } \\
\text { dokter gigi }\end{array}$ \\
\hline 4. & $\begin{array}{c}\text { Puskesmas } \\
\text { Ciasem }\end{array}$ & - & $\mathrm{v}$ & $\begin{array}{c}\text { Belum ada } \\
\text { pelatihan }\end{array}$ \\
\hline & $\begin{array}{c}\text { Pamanukan } \\
\text { Pasmas }\end{array}$ & - & $\mathrm{v}$ & $\begin{array}{c}\text { Belum ada } \\
\text { pelatihan }\end{array}$ \\
\hline
\end{tabular}

Tabel 1.6

Pelayanan dalam rangka pelimpahan wewenang sebagaimana dimaksud pada ayat (2) meliputi pelayanan kesehatan gigi dan mulut sesuai dengan kompetensi tambahan yang diperoleh

\footnotetext{
${ }^{22}$ Hasil penelitian diolah
}

melalui pelatihan (Permenkes Nomor 20 Tahun 2016 Pasal 20 ayat 3$)^{23}$

\begin{tabular}{|c|c|c|c|c|}
\hline No. & Puskesmas & $\begin{array}{c}\text { Ses } \\
\text { uai }\end{array}$ & $\begin{array}{c}\text { Tidak } \\
\text { Sesuai }\end{array}$ & $\begin{array}{c}\text { Hambatan } \\
\text { / Kendala }\end{array}$ \\
\hline 1. & $\begin{array}{c}\text { Puskesmas } \\
\text { Karangany } \\
\text { ar }\end{array}$ & - & $\mathrm{v}$ & $\begin{array}{c}\text { Tidak ada } \\
\text { dokter gigi }\end{array}$ \\
\hline 2. & $\begin{array}{c}\text { Puskesmas } \\
\text { Pusakanega } \\
\text { ra }\end{array}$ & - & $\mathrm{v}$ & $\begin{array}{c}\text { Tidak ada } \\
\text { dokter gigi }\end{array}$ \\
\hline 3. & $\begin{array}{c}\text { Puskesmas } \\
\text { Ciasem }\end{array}$ & - & $\mathrm{v}$ & $\begin{array}{c}\text { Belum ada } \\
\text { pelatihan }\end{array}$ \\
\hline 4. & $\begin{array}{c}\text { Puskesmas } \\
\text { Pamanukan }\end{array}$ & - & $\mathrm{v}$ & $\begin{array}{c}\text { Belum ada } \\
\text { pelatihan }\end{array}$ \\
\hline
\end{tabular}

Tabel 1.7

Pelatihan sebagaimana dimaksud pada ayat (2) dan ayat (3) merupakan tanggung jawab pemerintah daerah provinsi dan/atau pemerintah daerah kabupaten/kota bekerja sama dengan Organisasi Profesi dan melibatkan organisasi profesi terkait lainnya (Permenkes Nomor 20 Tahun 2016 Pasal 20 ayat 4) ${ }^{24}$

\begin{tabular}{|c|c|c|c|c|}
\hline No. & Puskesmas & $\begin{array}{c}\text { Ses } \\
\text { uai }\end{array}$ & $\begin{array}{c}\text { Tidak } \\
\text { Sesuai }\end{array}$ & $\begin{array}{c}\text { Hambatan } \\
\text { / Kendala }\end{array}$ \\
\hline 1. & $\begin{array}{c}\text { Puskesmas } \\
\text { Karanganya } \\
\text { r }\end{array}$ & - & $\mathrm{v}$ & $\begin{array}{c}\text { Belum } \\
\text { dilaksanak } \\
\text { an }\end{array}$ \\
\hline 3. & $\begin{array}{c}\text { Puskesmas } \\
\text { Pusakanega } \\
\text { ra }\end{array}$ & - & $\mathrm{v}$ & $\begin{array}{c}\text { Belum } \\
\text { dilaksanak } \\
\text { an }\end{array}$ \\
\hline 4. & $\begin{array}{c}\text { Puskesmas } \\
\text { Pamanukan }\end{array}$ & - & $\mathrm{v}$ & $\begin{array}{c}\text { Belum } \\
\text { dilaksanak } \\
\text { an }\end{array}$ \\
\hline & - & $\mathrm{v}$ & $\begin{array}{c}\text { Belum } \\
\text { dilaksanak } \\
\text { an }\end{array}$ \\
\hline
\end{tabular}

\section{Tabel 1.8}

Pelatihan sebagaimana dimaksud pada ayat (2) dan ayat (4) harus terakreditasi sesuai

\footnotetext{
${ }^{23}$ Hasil penelitian diolah

${ }^{24}$ Hasil penelitian diolah
} 
ketentuan peraturan perundang - undangan (Permenkes Nomor 20 Tahun 2016 Pasal 20 ayat $5)^{25}$

\begin{tabular}{|c|c|c|c|c|}
\hline No. & Puskesmas & $\begin{array}{c}\text { Ses } \\
\text { uai }\end{array}$ & $\begin{array}{c}\text { Tidak } \\
\text { Sesuai }\end{array}$ & $\begin{array}{c}\text { Hambatan / } \\
\text { Kendala }\end{array}$ \\
\hline 1. & $\begin{array}{c}\text { Puskesmas } \\
\text { Karangany } \\
\text { ar }\end{array}$ & - & $\mathrm{v}$ & $\begin{array}{c}\text { Belum ada } \\
\text { pelatihan }\end{array}$ \\
\hline 2. & $\begin{array}{c}\text { Puskesmas } \\
\text { Pusakanega } \\
\text { ra }\end{array}$ & - & $\mathrm{v}$ & $\begin{array}{c}\text { Belum ada } \\
\text { pelatihan }\end{array}$ \\
\hline 3. & $\begin{array}{c}\text { Puskesmas } \\
\text { Ciasem }\end{array}$ & - & $\mathrm{v}$ & $\begin{array}{c}\text { Belum ada } \\
\text { pelatihan }\end{array}$ \\
\hline 4. & $\begin{array}{c}\text { Puskesmas } \\
\text { Pamanukan }\end{array}$ & - & $\mathrm{v}$ & $\begin{array}{c}\text { Belum ada } \\
\text { pelatihan }\end{array}$ \\
\hline
\end{tabular}

Tabel 1.9

Pelimpahan wewenang berdasarkan penugasan pemerintah hanya dapat dilaksanakan di Fasilitas Pelayanan Kesehatan milik Pemerintah dan/atau pemerintah daerah (Permenkes Nomor 20 Tahun 2016 Pasal 20 ayat 6)

\begin{tabular}{|c|c|c|c|c|}
\hline No. & Puskesmas & $\begin{array}{c}\text { Ses } \\
\text { uai }\end{array}$ & $\begin{array}{c}\text { Tidak } \\
\text { Sesuai }\end{array}$ & $\begin{array}{c}\text { Hambatan / } \\
\text { Kendala }\end{array}$ \\
\hline 1. & $\begin{array}{c}\text { Puskesmas } \\
\text { Karangany } \\
\text { ar }\end{array}$ & - & - & $\begin{array}{c}\text { Tidak } \\
\text { adanya } \\
\text { dokter gigi }\end{array}$ \\
\hline 2. & $\begin{array}{c}\text { Puskesmas } \\
\text { Pusakaneg } \\
\text { ara }\end{array}$ & - & - & $\begin{array}{c}\text { Tidak ada } \\
\text { dokter gigi }\end{array}$ \\
\hline 3. & $\begin{array}{c}\text { Puskesmas } \\
\text { Ciasem }\end{array}$ & - & - & - \\
\hline 4. & $\begin{array}{c}\text { Puskesmas } \\
\text { Pamanuka } \\
\mathrm{n}\end{array}$ & - & - & - \\
\hline
\end{tabular}

Tabel 1.10

Dalam hal daerah sebagaimana dimaksud dalam Pasal 20 ayat (1) telah terdapat dokter gigi, wewenang untuk melakukan pelayanan berdasarkan penugasan pemerintah tidak

\footnotetext{
${ }^{25}$ Hasil penelitian diolah

${ }^{26}$ Hasil penelitian diolah
}

berlaku (Permenkes Nomor 20 Tahun 2016 Pasal 21) ${ }^{27}$

\begin{tabular}{|c|c|c|c|c|}
\hline No. & Puskesmas & $\begin{array}{c}\text { Ses } \\
\text { uai }\end{array}$ & $\begin{array}{c}\text { Tidak } \\
\text { Sesuai }\end{array}$ & $\begin{array}{c}\text { Hambatan } \\
\text { / Kendala }\end{array}$ \\
\hline 1. & $\begin{array}{c}\text { Puskesmas } \\
\text { Karanganya } \\
\text { r }\end{array}$ & - & - & $\begin{array}{c}\text { Tidak ada } \\
\text { dokter gigi }\end{array}$ \\
\hline 2. & $\begin{array}{c}\text { Puskesmas } \\
\text { Pusakanega } \\
\text { ra }\end{array}$ & - & - & $\begin{array}{c}\text { Tidak ada } \\
\text { dokter gigi }\end{array}$ \\
\hline 3. & $\begin{array}{c}\text { Puskesmas } \\
\text { Ciasem }\end{array}$ & - & $\mathrm{v}$ & $\begin{array}{c}\text { Saling } \\
\text { membantu }\end{array}$ \\
\hline 4. & $\begin{array}{c}\text { Puskesmas } \\
\text { Pamanukan }\end{array}$ & - & $\mathrm{v}$ & $\begin{array}{c}\text { Saling } \\
\text { membantu }\end{array}$ \\
\hline
\end{tabular}

Dari tabel tersebut dijelaskan bahwa Puskesmas yang tidak ada dokter gigi masih ada yang mengerjakan tindakan pencabutan lebih dari satu akar dan ada yang melakukan rujukan sesuai kompetensi. Sedangkan yang ada dokter giginya, mereka kolaborasi dimana saling membantu agar pasien dapat tertangani. Pelimpahan wewenang diharapkan sesuai dengan peraturan agar diselenggarakannya pelatihan. Dilaksanakannya pelatihan untuk mningkatkan ketrampilan (skill) dan pengetahuan khususnya bagi terapis gigi mulut.

Implementasi Terapis gigi mulut adalah kewenangan mandat. Mandat tidak terjadi suatu pemberian wewenang baru maupun pelimpahan wewenang dari Badan atau Pejabat TUN yang satu kepada yang lain. Tanggung jawab kewenangan atas dasar

\footnotetext{
${ }^{27}$ Hasil penelitian diolah
} 
mandat masih tetap pada pemberi mandat, tidak beralih kepada penerima mandat. Mandat diartikan suatu pelimpahan wewenang kepada bawahan. Pelimpahan itu bermaksud memberi wewenang kepada bawahan untuk membuat keputusan a/n pejabat Tata Usaha Negara yang memberi mandat. Tanggung jawab tidak berpindah ke mandataris, melainkan tanggung jawab tetap berada di tangan pemberi mandat, hal ini dapat dilihat dari kata a.n (atas nama). Dengan demikian tugas terapis gigi mulut yang diberikan oleh dokter gigi sedangkan di Permenkes No. 20 Tahun 2016 tentang Izin dan Penyelenggaraan Praktik Terapis Gigi dan Mulut dijelaskan bahwa kewenangan dilakukan jika Puskesmas yang tidak ada dokter giginya dan itu ada surat keputusan dari Pemerintah. Terapis gigi mulut mengerjakan kompetensi dokter gigi dengan alasan keduanya saling membantu dikarenakan pasien banyak dalam sehari. Adanya terapis gigi mulut yang mengerjakan tindakan baik yang kompetensi atau bukan kompetensi terapis gigi mulut dengan biaya tidak sesuai peraturan daerah Kabupaten Subang.

Beberapa Puskesmas di Kabupaten Subang dalam menjalankan suatu tindakan sesuai kompetensi dan merupakan kewenangannya masih melakukan kolaborasi dikarenakan banyaknya pasien dan yang tidak ada dokter gigi dilakukan rujukan da nada beberapa yang ditangani sendiri jika masih bisa dikerjakan namun hal ini perlu pemantauan dan pengarahan dari dinas kesehatan terkait kewenangan dan kompetensi yang tercantun dalam Peraturan Daerah Kabupaten Subang dan Permenkes No. 20 Tahun 2016.

\section{PENUTUP}

\section{Kesimpulan}

a. Implementasi kewenangan terapis gigi mulut menurut Permenkes No. 20 tahun 2016 tentang Izin Penyelenggaraan Praktik Terapis Gigi dan Mulut dihubungkan dengan kompetensi terapis gigi mulut di wilayah kerja Puskesmas kabupaten Subang dalam melakukan tindakan ada beberapa yang sesuai dan ada beberapa yang tidak sesuai dengan Permenkes No. 20 tahun 2016. Beberapa yang tidak sesuai di Puskesmas kabupaten Subang diantaranya terdapat dokter gigi tetapi terapis gigi mulut melakukan tindakan pencabutan lebih dari satu akar dan penambalan lebih dari dua bidang berdasarkan mandat secara tidak tertulis dari dokter gigi dengan alasan saling membantu karena banyaknya pasien. Dengan demikian jika terjadi suatu hal, maka yang bertanggung jawab adalah pemberi pelimpahan kewenangan sedangkan Puskesmas yang tidak ada dokter gigi melakukan tindakan di luar kewenangan tanpa ada penugasan dari 
pemerintah dan pelatihan serta beberapa tidak dilakukan rujukan. Kedua hal tersebut tidak sesuai dengan kompetensi terapis gigi mulut. Dengan demikian terapis gigi mulut yang bertanggung jawab atas tindakan.

b. Upaya menangani pelaksanaan kewenangan terapis gigi mulut menurut Permenkes No. 20 tahun 2016 tentang Izin Penyelenggaraan Praktik Terapis Gigi dan Mulut dihubungkan dengan kompetensi terapis gigi mulut di wilayah kerja Puskesmas kabupaten Subang antara lain mempertegas aturan agar dilaksanakan secara berkesinambungan, melakukan pembinaan sumber daya manusia melalui pelatihan, melakukan pengawasan agar tertib dalam hal kewenangan sesuai kompetensi, dan melakukan requitment sumber daya manusia.

\section{Saran}

a. Bagi terapis gigi mulut agar melakukan pelatihan

b. Bagi terapis gigi mulut yang belum melakukan rujukan, agar peraturan daerah Kabupaten Subang dijelaskan adanya rujukan tertulis seperti peraturan daerah kabupaten Bandung

c. Bagi dokter gigi dalam pelimpahan wewenang mandat diharapkan secara tertulis

d. Bagi Puskesmas mengikutsertakan terapis gigi mulut mengikuti pelatihan e. Organisasi profesi bekerjasama dengan dinas kesehatan provinsi untuk mengadakan pelatihan terkait kesesuaian kompetensi dan tambahan kompetensi yang tertuang dalam Permenkes No 20 Tahun 2016 tetapi sebelum terselenggaranya pelatihan diharapkan adanya diklat untuk memperbanyak modul terlebih dahulu

f. Dinas Kesehatan Kabupaten Subang dalam hal ini diharapkan melakukan pembinaan dan pengawasan bekerjasama dengan Persatuan Terapis Gigi Mulut Indonesia mengenai kewenangan terapis gigi dan mulut agar sesuai dengan Permenkes No. 20 Tahun 2016 dan melakukan penambahan tenaga dokter gigi di Puskesmas tersebut.

\section{DAFTAR PUSTAKA}

AzrulAzwar,

PengantarAdministrasiKesehat

an, Jakarta, BinarupaAksara, 1996.

DediAlamsyah,

ManajemenPelayananKesehata

n, Yogyakarta, NuhaMedika, 2011.

Depkes RI, Rencana Pembangunan JangkaPanjangBidangKesehata n 2005 - 2025, Jakarta, 2009. 
DPP PPGI, StandarKompetensiTerapis Gigi danMulut Indonesia, Jakarta, 2017.

Handayani L, Sopacua E, Siswanto, Ma'ruf NA \&Widjiartini, Upayarevitalisasipelayanankes ehatanPuskesmasdanjaringann yadalamrangkapeningkatankua litaspelayanankesehatan, Surabaya, LaporanPenelitian, PuslitbangSistemdanKebijakan Kesehatan, 2006.

SoekidjoNotoatmojo,

IlmuPerilakuKesehatan,

Jakarta, Penerbit PT. Rineka Citra, 2010.

SumberPusat Data danInformasi, Kemenkes RI, 2017.

\section{PERATURAN - PERATURAN}

Undang - Undang RI No 36 Tahun 2009 TentangKesehatan.

Undang - Undang RI Nomor 36 Tahun 2014 TentangTenagaKesehatan.

Undang - UndangDasar 1945 Pasal 28

$\mathrm{H}$ ayat

TentangHakAsasiManusia,

Jakarta, 1945.

PermenkesNomor 20 Tahun 2016

TentangIzindanPenyelenggaraa
nPraktikTerapis Gigi danMulut, Jakarta.

PermenkesNomor $\quad 80 \quad$ Tahun 2016 TentangPenyelenggaraanPekerj aanAsistenTenagaKesehatan.

Peraturan Daerah KabupatenSubangNomor Tahun 2007.

\section{ARTIKEL \\ http://pkmpusakanagara.blogspot.com/200 9/06/profil-pkm-pusakanagara_08.html}


Devy Octaviana, Kewenangan Terapis Gigi Mulut Menurut Permenkes No. 20 Tahun 2016 Tentang Izin... 